\title{
Ground response to rolling dynamic compaction
}

\author{
B. SCOTT*, M. JAKSA $†$ and P. MITCHELL $†$
}

\begin{abstract}
Rolling dynamic compaction (RDC) is typically used for improving ground in situ or compacting fill in thick lifts. In many project applications, the effects of RDC are verified by way of testing that is undertaken pre- and/or post-compaction. This study presents results from a full-scale field trial that involved placing an earth pressure cell (EPC) and accelerometers at a depth of $0.7 \mathrm{~m}$ within a $1.5 \mathrm{~m}$ thick layer of homogeneous sandy gravel to measure the response to RDC in real-time. Double integration of acceleration-time data enabled settlement to be inferred, while the EPC measured the change in stress due to impact. The maximum change in vertical stress recorded over the 80 passes undertaken was approximately $1100 \mathrm{kPa}$. During a typical module impact, the loading and unloading response occurred over a duration of approximately $0.05 \mathrm{~s}$. The acceleration response of RDC was measured in three orthogonal directions, with the vertical accelerations dominant.
\end{abstract}

KEYWORDS: compaction; field instrumentation; ground improvement

Published with permission by the ICE under the CC-BY 4.0 license. (http://creativecommons.org/licenses/by/4.0/)

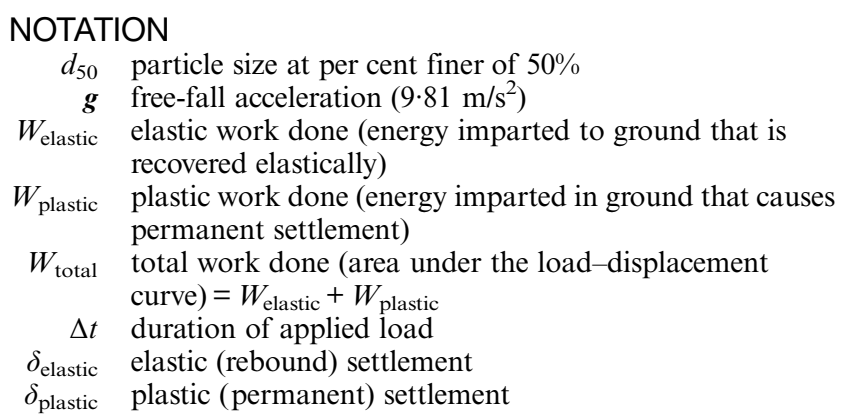

\section{INTRODUCTION}

Rolling dynamic compaction (RDC) imparts energy to the ground through the use of a heavy, non-circular module that falls to impact the ground. A limitation of many past field investigations to verify the effects of RDC is that testing is typically performed pre- and/or post-compaction. Such investigations often serve their intended purpose for determining if a project specification has been met (or otherwise) but they do not capture the dynamic effects of a heavy module impacting the ground in real-time. This study has used a buried earth pressure cell (EPC) and accelerometers to better understand the ground response beneath the surface during the passage of an impact roller.

Manuscript received 19 November 2018; first decision 27 January 2019; accepted 26 February 2019.

Published online at www.geotechniqueletters.com on 23 April 2019.

*School of Civil, Environmental \& Mining Engineering, The University of Adelaide, Adelaide, Australia

(Orcid:0000-0001-5409-7678).

†School of Civil, Environmental \& Mining Engineering, The University of Adelaide, Adelaide, Australia (Orcid:0000-0003-3756-2915).

$\$$ Aurecon, Adelaide, Australia; School of Civil, Environmental \& Mining Engineering, The University of Adelaide, Adelaide, Australia (Orcid:0000-0002-6811-4122).

\section{BACKGROUND}

Impact rollers with different module masses, shapes and drop heights, have been compared to predict the energy imparted into the ground (McCann, 2015). A limitation with such a prediction is that a RDC module that is towed across the surface impacts the ground in a different manner to a dynamic compaction pounder that is a function of mass, drop height and vertical acceleration due to gravity. An RDC module, shown in Fig. 1, impacts the ground in a similar way to a falling hinged trap door; the geometry and surface area of the module that is in contact with the ground is non-uniform; as is the impact velocity of the module when it contacts the ground.

In RDC applications, accelerometers have been placed on an impact roller to measure the ground surface response. Heyns (1998) and McCann \& Schofield (2007) both noted that an increase in the magnitude of decelerations is commonly measured with increasing passes, as the surface soil stiffness increases. This finding is consistent with the work of Clifford (1978), who observed that the module drop height increases as the ground surface becomes harder; the cross-sectional area of the module that is in contact with the ground changes with drop height due to the geometry of the rounded corners and how far they embed in the ground. The energy imparted by the roller is spread over a smaller area as the stiffness of the surficial soil increases; this results in greater contact pressures being imparted to the soil with increasing passes. The use of module-mounted accelerometers has proven useful in identifying less stiff nearsurface soils that typically exhibit lower decelerations (McCann \& Schofield, 2007); however, there is no guarantee that measuring the response of an impact roller as it passes over the ground surface gives a true indication of the soil response below the surface. Inferring improvement due to RDC from surface measurements can be challenging given RDC typically disturbs the near-surface soils, which can be further complicated by sites containing inherent soil variability. Mooney \& Rinehart (2007) carried out a field investigation using a smooth drum vibrating roller. They performed multiple passes across test areas comprising both heterogeneous and homogeneous soils. They found that soil heterogeneity presented significant challenges for 
interpreting instrumented roller data. This study overcomes previous limitations by attaching accelerometers to an EPC and burying them in homogeneous fill material to quantify the loading induced stress and ground deceleration beneath the ground surface, yet within the expected zone of influence of RDC.

\section{Comparisons with dynamic compaction}

Measuring the ground response of deep dynamic compaction has been studied by Mayne \& Jones (1983), who attached an accelerometer to a $20.9 \mathrm{t}$ pounder to monitor the deceleration on impact with the ground surface after falling a distance of $18.3 \mathrm{~m}$; the deceleration-time response of the impact blow occurred over a duration of only $0.05 \mathrm{~s}$. Also of significance is the magnitude of decelerations recorded was in the order of $70-85 \mathrm{~g}$, and a trend of increasing magnitude with number of drops was observed. Clegg (1980) attached an accelerometer to a falling weight and found that the peak deceleration of the weight on impact with the soil was directly related to the soil resistance, described as a combination of both soil stiffness and shearing resistance. Chow et al. (1990) developed a theoretical framework that was based on matching deceleration measurements of a dynamic compaction pounder impacting the ground using an accelerometer that was attached to the pounder near the centre of gravity. The one-dimensional model that was developed was similar to pile driving analyses where the impact velocity was obtained by integrating measured decelerations. Yu (2004) double integrated the acceleration-time response of a vertically falling plate to generate the load-displacement relationship, which was integrated to quantify the work done. Analysis of a loaddisplacement response due to impact was also undertaken by Jha et al. (2012), who investigated energy dissipation to quantify the elastic energy that was recovered during unloading of multi-phase cementitious materials. They plotted the load-displacement response for cementitious materials subjected to nano-indentation and determined the area under the loading and unloading curves and quantified the

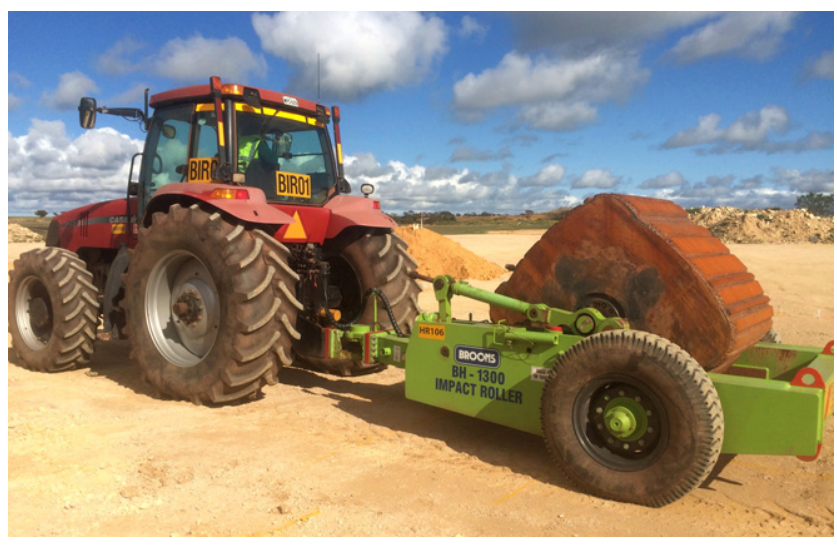

Fig. 1. Eight tonne four-sided impact roller work done. The key aims of this study are to measure the loading-induced stresses and displacements that soil particles beneath the ground surface experience, and to quantify the work done from measured force-displacement data.

\section{RESEARCH TEST SITE}

Figure 1 shows a four-sided $8 \mathrm{t}$ impact roller $(1450 \mathrm{~mm}$ square and $1300 \mathrm{~mm}$ wide module) that was used at a dedicated research site located at Monarto Quarries, approximately $60 \mathrm{~km}$ south-east of Adelaide, Australia. While conducting a full-scale trial that is not associated with a client-funded project is expensive, a research focused trial provided an ability to control a number of variables that can often conceal the true effects of RDC. Significantly, natural soil was excavated to a depth of $1.5 \mathrm{~m}$ and replaced with homogeneous fill; a crushed rock with a maximum particle size of $20 \mathrm{~mm}$ that was readily available and locally produced at the quarry. Six equal lifts of $250 \mathrm{~mm}$ thickness were adopted; the material was placed using a Volvo L150E loader, and was lightly compacted using a $60 \mathrm{~kg}$ vibrating plate and wheel rolling from the loader. The fill material was classified as a well-graded sandy gravel (GW) in accordance with the Unified Soil Classification System. The fill was tested for homogeneity through the use of particle-size distribution and Proctor compaction testing; the results are given in Table 1.

\section{EPCs and accelerometers}

Field trials undertaken by Avalle et al. (2009) and Scott et al. (2016) using the four-sided impact roller have shown that a module impacting the ground directly above embedded instrumentation results in significantly higher ground decelerations being recorded, compared with when the module strikes the ground off-set from embedded instrumentation. A limitation of burying equipment at discrete locations is that it is not possible to capture the maximum ground response from every impact. However, a key advantage of this technique is that it does provide real-time data on dynamic pressures and accelerations that are imparted into the ground that other testing methods are unable to do.

A custom-built accelerometer cluster consisting of $\pm 5 \mathrm{~g}$ and $\pm 16 \mathrm{~g}$ accelerometers in the $Z$-plane to measure vertical acceleration, and $\pm 5 g$ accelerometers in the $X$ - and $Y$-planes, to measure tilt perpendicular to, and in the direction of travel, respectively. A total of 80 passes were undertaken. The accelerometer cluster was attached to an EPC (230 mm diameter and $6 \mathrm{~mm}$ thick) that was buried at a depth of $0.7 \mathrm{~m}$ below the ground surface, and connected to a bespoke data-acquisition system and Labview software program (refer Labview (2018)). The ability to capture an accurate ground response using EPCs and accelerometers relies heavily on adopting a sufficiently high sampling frequency. Given that displacement is to be quantified from the double integration of acceleration-time data, a sampling frequency of $4 \mathrm{kHz}$ (twice that adopted by Avalle et al., 2009) was selected for this trial to ensure that the true peak pressure and ground deceleration could be accurately captured. As

Table 1. Particle-size distribution, compaction and field moisture test results of fill material

\begin{tabular}{l|c|c|c|c|c|c|c|c|c}
\hline Material & $\begin{array}{c}d_{50}: \\
\mathrm{mm}\end{array}$ & $\begin{array}{c}\text { Gravel } \\
\text { size: } \%\end{array}$ & $\begin{array}{c}\text { Sand } \\
\text { size: } \%\end{array}$ & Fines: \% & $\begin{array}{c}\text { Standard } \\
\text { OMC: } \%\end{array}$ & $\begin{array}{c}\text { Standard } \\
\text { MDD: } \mathrm{kN} / \mathrm{m}^{3}\end{array}$ & FMC: \% & $\begin{array}{c}\text { Modified } \\
\text { OMC: \% }\end{array}$ & $\begin{array}{c}\text { Modified } \\
\text { MDD: kN/m }\end{array}$ \\
\hline $\begin{array}{c}20 \mathrm{~mm} \text { crushed } \\
\text { rock }\end{array}$ & $4 \cdot 0$ & 57 & 40 & 3 & $7 \cdot 9$ & $17 \cdot 9$ & $8 \cdot 6$ & $7 \cdot 2$ & $18 \cdot 9$ \\
\hline
\end{tabular}

$d_{50}$, particle size at per cent finer of 50\%; OMC, optimum moisture content; MDD, maximum dry density; FMC, field moisture content. 
discussed by Thong et al. (2002), faster sampling rates can improve the accuracy of integration, but errors can increase with the duration of the time interval over which integration is undertaken.

\section{RESULTS AND DISCUSSION}

A single pass (54 summarised in Table 2) was selected out of the 80 passes undertaken for analysis as it featured a high peak pressure and the largest vertical deceleration recorded. In Fig. 2 the module impact resulted in a measured peak pressure of $1077 \mathrm{kPa}$ at a depth of $0.7 \mathrm{~m}$. It can be observed that the impulse pressure imparted to the ground was loaded and unloaded over a duration of approximately
0.05 s. Figure 3 illustrates the vertical $(Z$-) acceleration-time response for the same pass shown in Fig. 2, whereby a downward (negative) acceleration first occurs as the soil is loaded. In response to loading, the soil resistance is mobilised, which results in an upward acceleration before the acceleration trace dampens and returned to zero less than $0 \cdot 1 \mathrm{~s}$ after loading. Significantly, a peak deceleration (negative acceleration) of $21 \mathrm{~g}$ was measured before the soil resistance was mobilised. Table 3 includes a summary of passes 1-10, as well as every fifth pass thereafter. As observed in Table 3, the magnitude of the peak downward acceleration was typically greater than the peak upward acceleration, this trend was more defined for impacts that generated large accelerations. Consequently, a

Table 2. Summary of pass 54 for test depth of $0 \cdot 7 \mathrm{~m}$

\begin{tabular}{l|c|c|c|c|c|c|c|c|c}
\hline Pass & $\begin{array}{c}\delta_{\text {elastic }}: \\
\mathrm{mm}\end{array}$ & $\begin{array}{c}\delta_{\text {plastic }}: \\
\mathrm{mm}\end{array}$ & $\begin{array}{c}W_{\text {total }}: \\
\mathbf{J}\end{array}$ & $\begin{array}{c}W_{\text {elastic }}: \\
\mathbf{J}\end{array}$ & $\begin{array}{c}W_{\text {plastic }}: \\
\mathbf{J}\end{array}$ & $\begin{array}{c}\text { Peak pressure: } \\
\mathrm{kPa}\end{array}$ & $\begin{array}{c}\Delta t: \mathrm{s} \\
\text { Peak } \\
\text { deceleration: } \boldsymbol{g}\end{array}$ & $\begin{array}{c}\text { Peak } \\
\text { acceleration: } \boldsymbol{g}\end{array}$ \\
\hline 54 & 4 & 5 & 254 & 36 & 218 & 1077 & $0 \cdot 05$ & $-21 \cdot 0$ \\
\hline
\end{tabular}

$\delta_{\text {elastic }}$, rebound settlement; $\delta_{\text {plastic }}$, permanent settlement; $W_{\text {total }}$, total area under load-displacement curve; $W_{\text {elastic }}$, elastic work done; $W_{\text {plastic}=}$ plastic work done; $\Delta t$, duration of applied load; peak dec., peak deceleration; peak acc., peak acceleration.

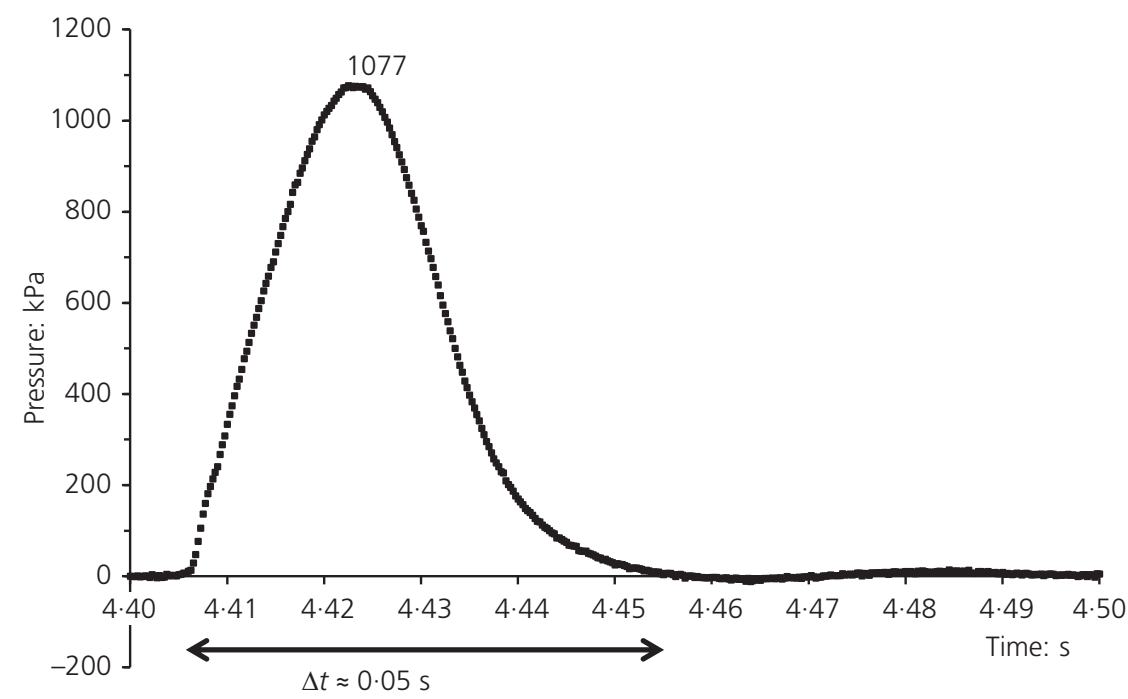

Fig. 2. Pressure distribution at time of module impact

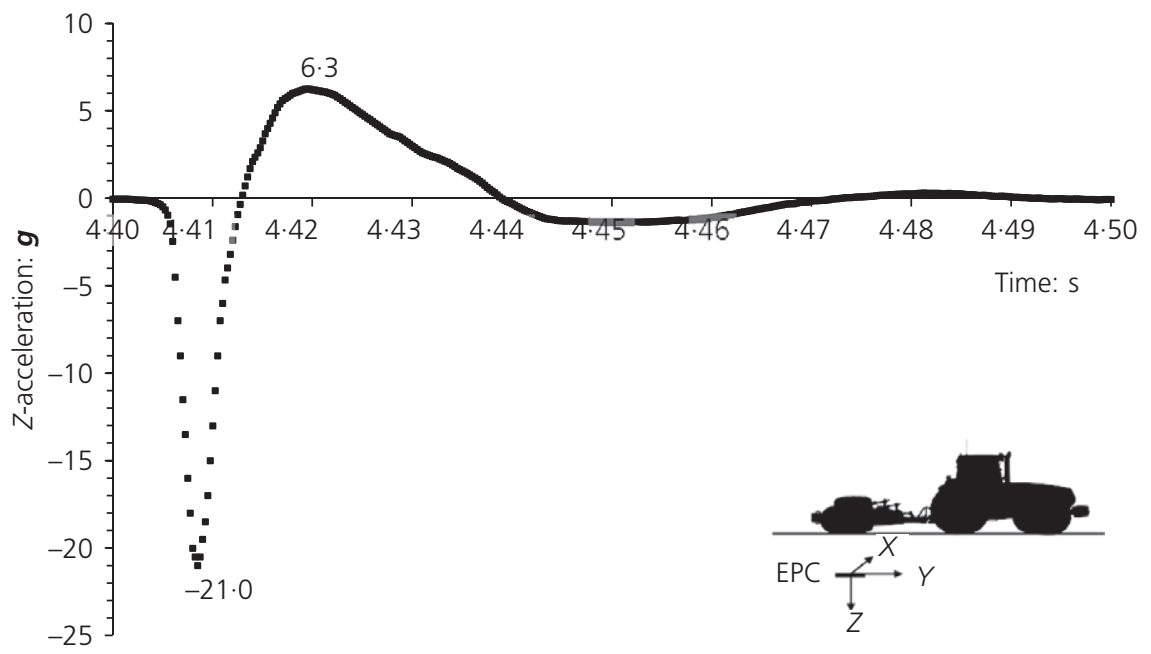

Fig. 3. Z-acceleration response at time of module impact 
shift in the baseline (zero) reading was undertaken that enabled readings of $-21 \mathrm{~g}$ and $+6 \cdot 3 \mathrm{~g}$ to be measured using a $\pm 16 \boldsymbol{g}$ accelerometer (range of $32 \mathrm{~g}$ ). Consistent with the findings of Mayne \& Jones (1983), an increased number of passes generally resulted in larger accelerations (and peak pressures) being recorded. However, the variable location of the module landing on the ground surface relative to buried instrumentation, analysed and discussed by Scott et al. (2016), was also a contributing factor that would explain why some passes (e.g. pass 54) yielded much larger peak pressures and vertical accelerations than others.
Figure 4 shows a plot of $Y$-acceleration (in the direction of travel of the roller) against time. Of significance in this plot is the larger magnitude of the positive (compared with negative) $Y$-acceleration. It can be inferred that the direction of travel of the module influences the ground response, an expected result given the module drop is not solely in a vertical direction. Figure 5 shows a plot of $X$-acceleration (perpendicular to the direction of travel) with time. Both positive and negative accelerations are approximately equal suggesting that the module landing directly over the centre of the cell produces a relatively symmetrical response in the direction across the test lane, this is not unexpected given the

Table 3. Summary of passes for test depth of $0.7 \mathrm{~m}$

\begin{tabular}{|c|c|c|c|c|c|c|c|c|c|}
\hline Pass & $\underset{\substack{\text { elastic: } \\
\mathrm{mm}}}{ }$ & $\begin{array}{c}\delta_{\text {plastic }}: \\
\mathrm{mm}\end{array}$ & $W_{\text {total }}: \mathbf{J}$ & $W_{\text {elastic }}: \mathbf{J}$ & $W_{\text {plastic }}: \mathbf{J}$ & $\begin{array}{c}\text { Peak pressure: } \\
\text { kPa }\end{array}$ & $\begin{array}{l}\text { Impulse } \Delta t: \\
\mathrm{s}\end{array}$ & $\begin{array}{c}\text { Peak dec.: } \\
\boldsymbol{g}\end{array}$ & $\begin{array}{l}\text { Peak acc.: } \\
\boldsymbol{g}\end{array}$ \\
\hline 1 & $2 \cdot 0$ & $0 \cdot 5$ & 13 & 9 & 4 & 230 & 0.07 & $-3 \cdot 5$ & $3 \cdot 0$ \\
\hline 2 & 3 & 1 & 44 & 13 & 31 & 419 & $0 \cdot 07$ & $-5 \cdot 5$ & $3 \cdot 8$ \\
\hline 3 & $3 \cdot 5$ & $0 \cdot 5$ & 35 & 25 & 10 & 371 & $0 \cdot 08$ & $-5 \cdot 3$ & $4 \cdot 4$ \\
\hline 4 & 3 & 2 & 76 & 20 & 56 & 594 & $0 \cdot 08$ & $-4 \cdot 6$ & $2 \cdot 5$ \\
\hline 5 & $6 \cdot 5$ & 0 & 108 & 53 & 55 & 656 & $0 \cdot 07$ & $-5 \cdot 6$ & $7 \cdot 7$ \\
\hline 6 & 3 & 2 & 71 & 13 & 58 & 503 & $0 \cdot 06$ & $-11 \cdot 6$ & $5 \cdot 2$ \\
\hline 7 & 3 & 2 & 64 & 20 & 44 & 550 & 0.08 & $-2 \cdot 1$ & $3 \cdot 4$ \\
\hline 8 & 1 & 1 & 73 & 45 & 28 & 177 & $0 \cdot 08$ & $-1 \cdot 3$ & $0 \cdot 6$ \\
\hline 9 & 2 & 1 & 22 & 6 & 16 & 258 & $0 \cdot 05$ & $-4 \cdot 9$ & $2 \cdot 8$ \\
\hline 10 & 3 & 2 & 71 & 14 & 57 & 539 & $0 \cdot 06$ & $-8 \cdot 5$ & $3 \cdot 9$ \\
\hline 15 & 3 & 2 & 56 & 15 & 41 & 490 & $0 \cdot 08$ & $-4 \cdot 0$ & $1 \cdot 7$ \\
\hline 20 & 3 & 2 & 62 & 18 & 44 & 492 & 0.05 & $-9 \cdot 6$ & $4 \cdot 8$ \\
\hline 25 & $2 \cdot 5$ & $1 \cdot 5$ & 35 & 14 & 21 & 324 & $0 \cdot 06$ & $-8 \cdot 0$ & $4 \cdot 7$ \\
\hline 30 & 6 & $0 \cdot 5$ & 58 & 29 & 29 & 380 & 0.06 & $-10 \cdot 5$ & $9 \cdot 6$ \\
\hline 35 & $2 \cdot 5$ & 1 & 22 & 7 & 15 & 272 & $0 \cdot 05$ & $-4 \cdot 0$ & $2 \cdot 9$ \\
\hline 40 & 2 & 3 & 41 & 5 & 36 & 309 & $0 \cdot 04$ & $-6 \cdot 6$ & $4 \cdot 4$ \\
\hline 45 & $2 \cdot 5$ & 0.5 & 12 & 4 & 8 & 166 & $0 \cdot 05$ & $-1 \cdot 6$ & $2 \cdot 6$ \\
\hline 50 & 2 & 1 & 11 & 7 & 4 & 202 & $0 \cdot 06$ & $-1 \cdot 8$ & $1 \cdot 7$ \\
\hline 55 & $3 \cdot 5$ & $2 \cdot 5$ & 98 & 24 & 74 & 680 & $0 \cdot 05$ & $-7 \cdot 2$ & $5 \cdot 6$ \\
\hline 60 & $2 \cdot 5$ & $0 \cdot 5$ & 11 & 7 & 4 & 169 & 0.07 & $-2 \cdot 4$ & $2 \cdot 5$ \\
\hline 65 & $3 \cdot 5$ & $3 \cdot 5$ & 177 & 14 & 163 & 873 & $0 \cdot 05$ & $-13 \cdot 2$ & $5 \cdot 4$ \\
\hline 70 & 4 & $1 \cdot 5$ & 60 & 34 & 26 & 557 & 0.07 & $-4 \cdot 9$ & $3 \cdot 8$ \\
\hline 75 & $1 \cdot 5$ & 6 & 136 & 18 & 118 & 731 & 0.07 & $-9 \cdot 2$ & $4 \cdot 5$ \\
\hline 80 & $7 \cdot 5$ & $0 \cdot 5$ & 249 & 59 & 190 & 1115 & $0 \cdot 05$ & $-11 \cdot 2$ & $8 \cdot 0$ \\
\hline
\end{tabular}

$\delta_{\text {elastic }}$, rebound settlement; $\delta_{\text {plastic }}$, permanent settlement; $W_{\text {total }}$, total area under load-displacement curve; $W_{\text {elastic }}$, elastic work done;

$W_{\text {plastic }}$, plastic work done; $\Delta t$, duration of applied load; Peak dec., peak deceleration; Peak acc., peak acceleration, peak values in bold.

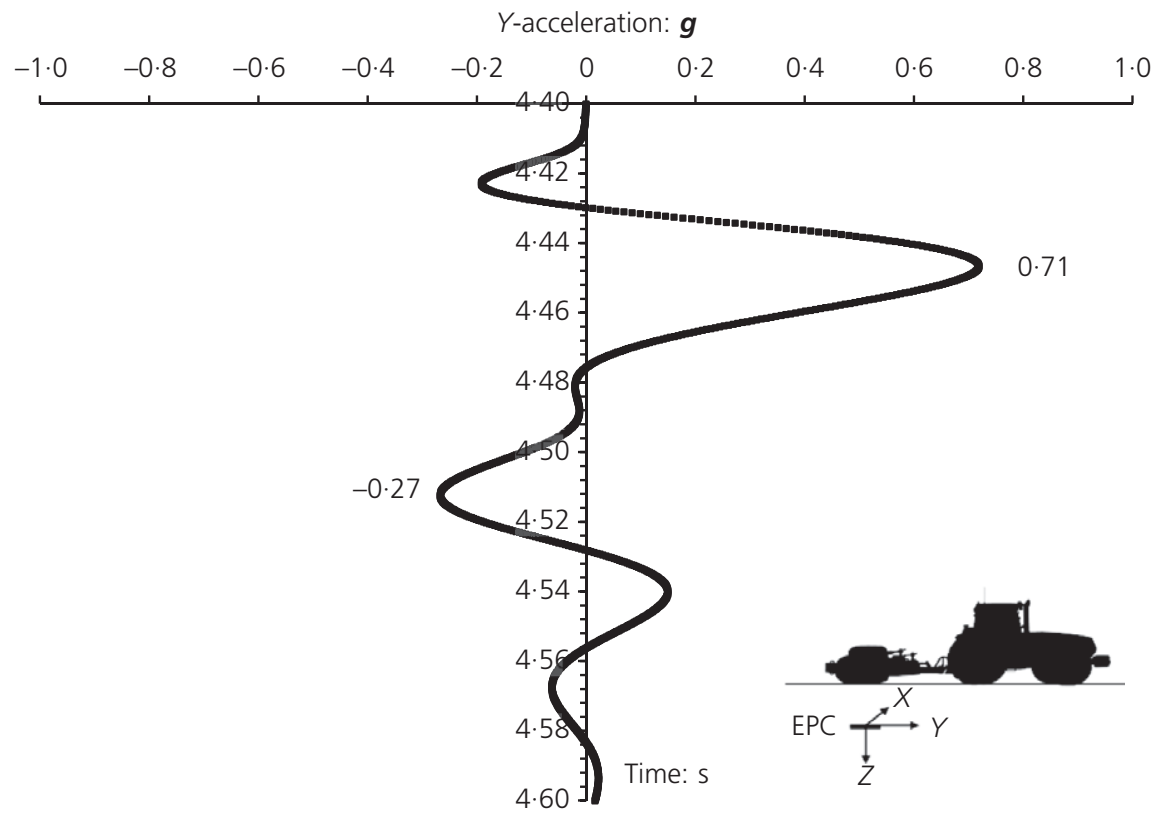

Fig. 4. $Y$-acceleration response at time of module impact 


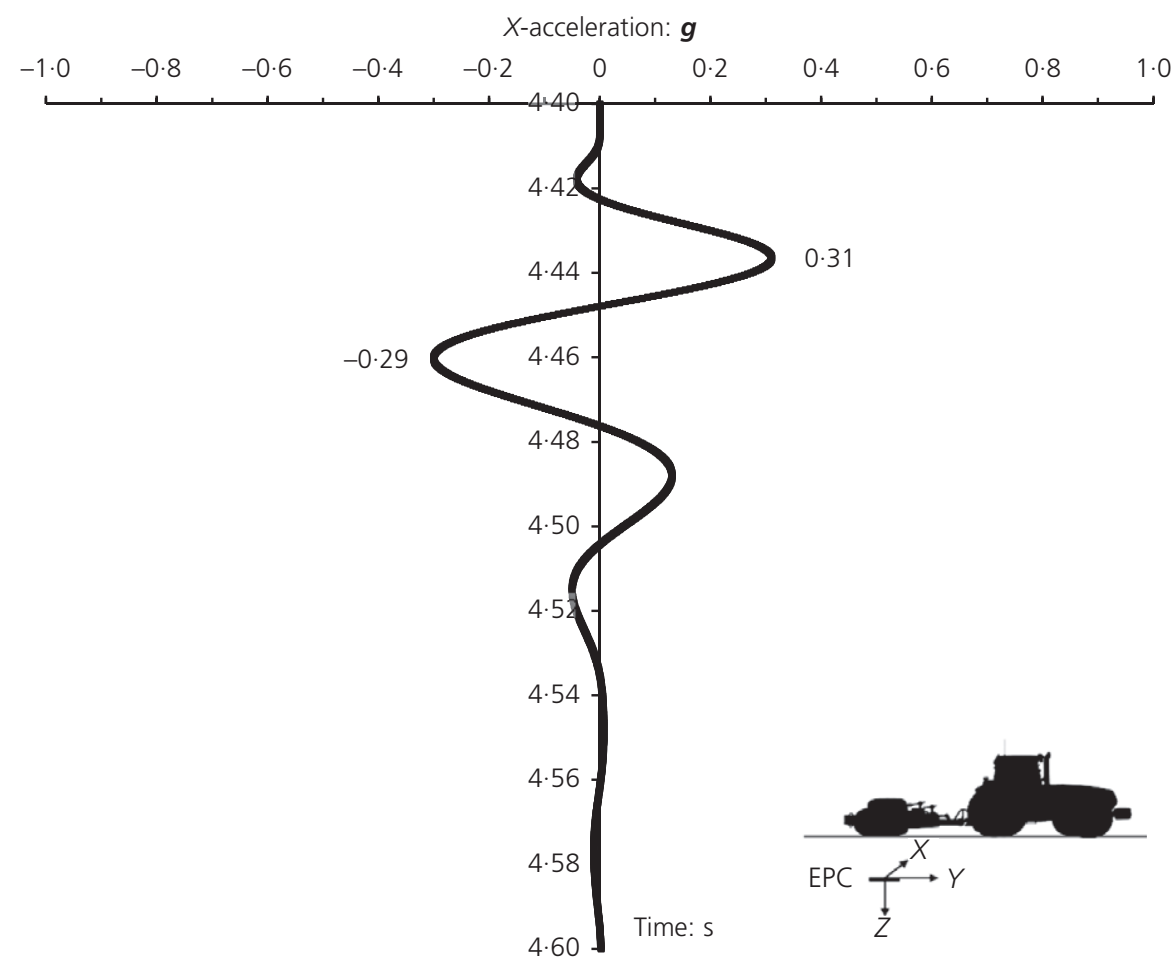

Fig. 5. $X$-acceleration response at time of module impact

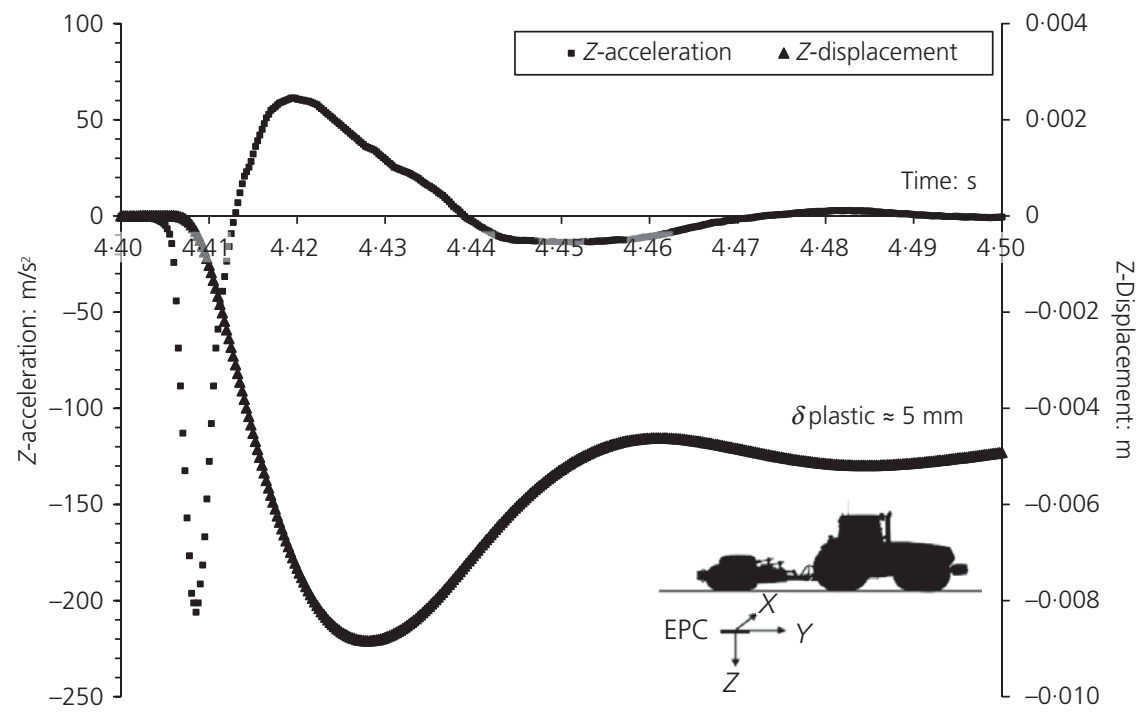

Fig. 6. Z-acceleration and Z-displacement against time

module only has a limited ability to move laterally within the trailer frame.

Figure 6 shows the variation of $Z$-acceleration and $Z$-displacement of the soil with time in response to a single module impact, whereby displacement was calculated from double integration of the acceleration-time response. From Fig. 6, it is evident that approximately $9 \mathrm{~mm}$ total displacement occurred due to loading; however, on unloading, the permanent displacement due to the single impact was $5 \mathrm{~mm}$. The same impact blow is illustrated in Fig. 7, which shows the loading and unloading response of the soil due to a single pass of the impact roller at a measured depth of $0.7 \mathrm{~m}$ beneath the ground surface. Force is determined by adopting the peak pressure at the time of impact and multiplying it by the plan area of the EPC. Displacement is evaluated from double integration of the acceleration-time response. In Fig. 7 the portion of the curve between points A and B represents the loading of the soil. The unloading portion of the curve is shown between points $\mathrm{B}$ and $\mathrm{C}$. The distance between points $\mathrm{A}$ and $\mathrm{C}$ provides a measure of the permanent deformation of the soil. For a perfectly elastic soil response with no hysteresis, $\mathrm{AB}$ and $\mathrm{BC}$ would be coincidental. Area $\mathrm{ABC}$ yields the plastic work done and the area CBD represents the elastic work that has been recovered during unloading. The total work done comprises both recoverable (elastic) and permanent (plastic) components.

Figure 8 shows the force-displacement response for consecutive module impacts (passes 1-10 inclusive, summarised in Table 3). As can be observed, there is a large variation in the shape and magnitudes of the force-displacement curves 


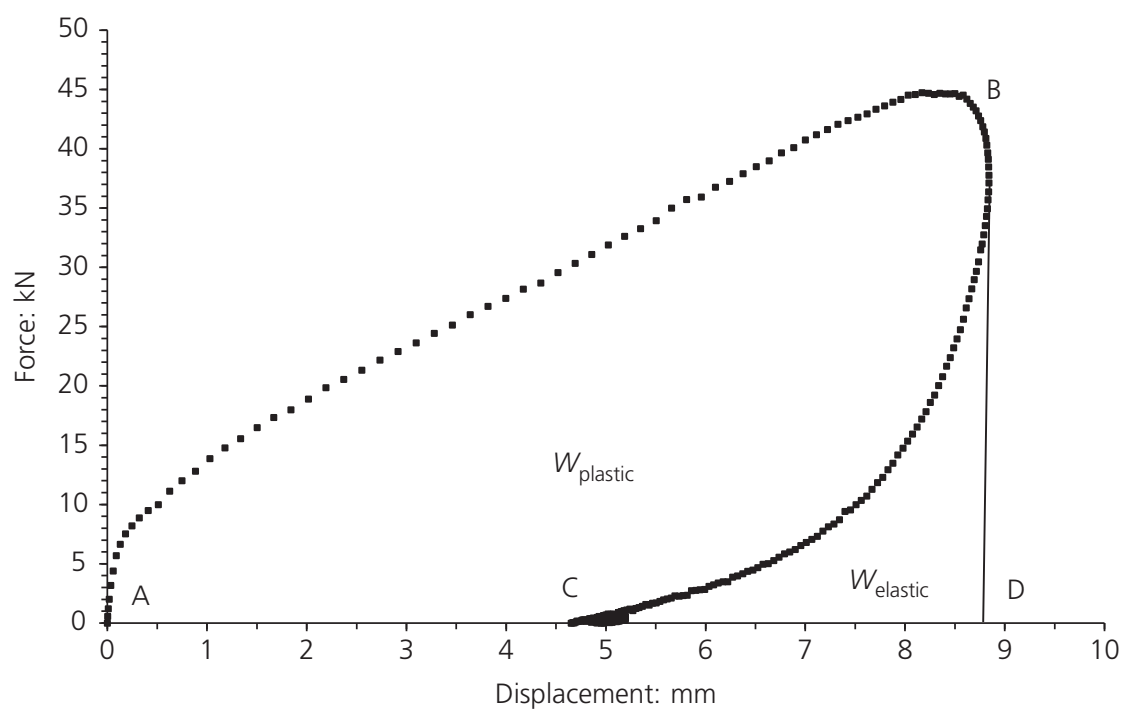

Fig. 7. Force-displacement curve for a single pass

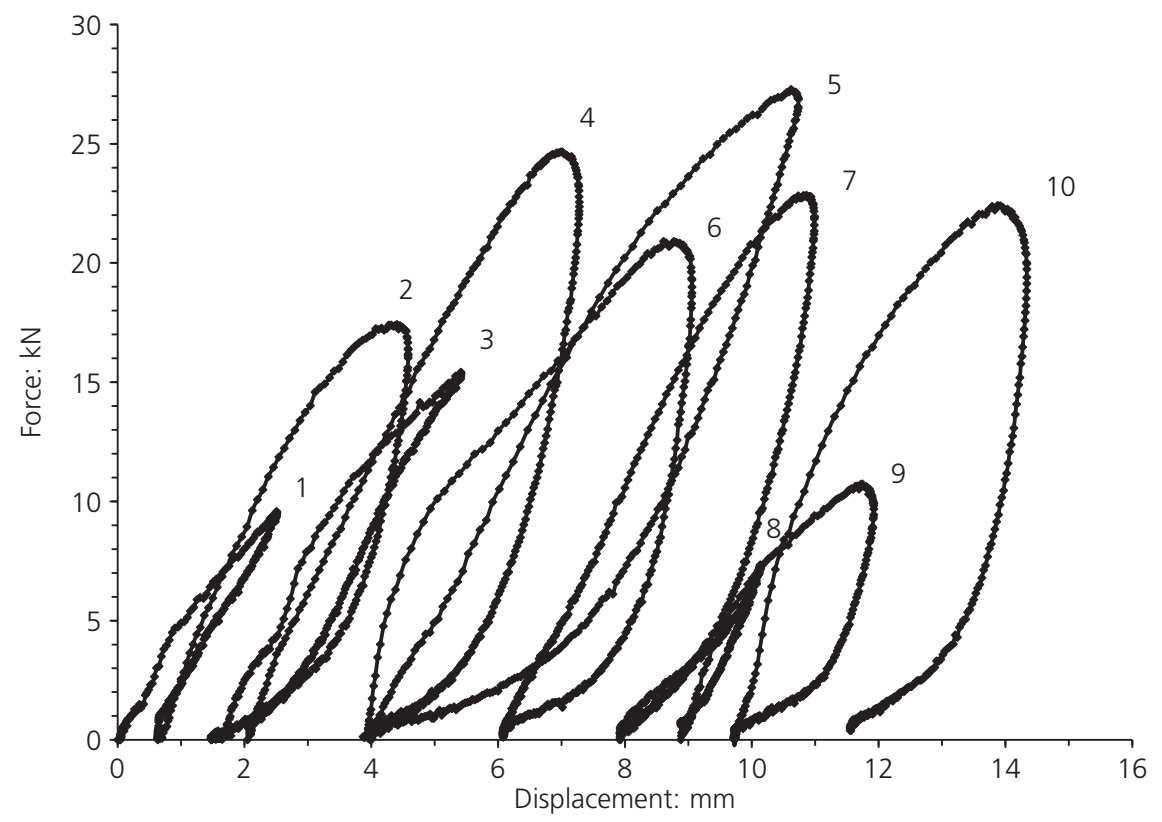

Fig. 8. Force-displacement curves for consecutive passes (1-10)

for individual passes. Pass 1 is close to an elastic impact where minimal work is done on the soil. The opposite is true for pass 10, which features a much larger area under the force-displacement curve.

\section{CONCLUSIONS}

To minimise soil variability, this study has captured the change in vertical stress due to RDC at a depth of $0.7 \mathrm{~m}$ beneath the surface using an EPC buried in a $1.5 \mathrm{~m}$ thick layer of homogeneous sandy gravel. The maximum change in vertical stress recorded over the 80 passes undertaken was approximately $1100 \mathrm{kPa}$. During a typical module impact, the loading and unloading of the soil occurred over a duration of roughly $0.05 \mathrm{~s}$. The acceleration response of a single module impact was also measured in three orthogonal directions at $0.7 \mathrm{~m}$ depth, with the vertical accelerations dominant. In project applications, there is typically a trade-off between layer thickness and the number of passes required to significantly improve ground to meet a certain specified criterion. While the number of passes (80) undertaken in this study was greater than what would economically be undertaken in practice, the results from buried instrumentation indicate that $0.7 \mathrm{~m}$ is well within the depth range that can be significantly improved by RDC. Quantifying the dynamic behaviour of the soil beneath the ground surface in real-time emphasises that the uneven module geometry results in some passes imparting much greater pressure to the ground than others, this being a key reason why many passes are needed to ensure adequate coverage of a site.

\section{ACKNOWLEDGEMENTS}

The authors acknowledge the following final year civil engineering students at the University of Adelaide who assisted with the field work referred to in this paper: Stefan Chenoweth, Jordan Colbert, Julianne Saw and Ross Vince. 
The authors are also indebted to instrumentation staff at the University of Adelaide who wrote the Labview software program and built the accelerometer clusters used in the field trial. The authors would also like to thank Cathy Cates for her help with word processing. The authors are grateful to $\mathrm{Mr}$ Stuart Bowes from Broons who provided financial and in-kind support; and Monarto Quarries personnel, who supplied plant and quarry material. Without their help and support, the work featured in this paper would not have been possible.

\section{REFERENCES}

Avalle, D. L., Scott, B. T. \& Jaksa, M. B. (2009). Ground energy and impact of rolling dynamic compaction - results from research test site. In Proceedings of the 17th international conference on soil mechanics and geotechnical engineering, Alexandria, Egypt (eds M. Hamza, M. Shahien and Y. El-Mossallamy), vol. 3, pp. 2228-2231. Amsterdam, the Netherlands: IOS Press BV.

Chow, Y. K., Yong, D. M., Yong, K. Y. \& Lee, S. L. (1990). Monitoring of dynamic compaction by deceleration measurements. Comput. Geotech. 10, No. 3, 189-209.

Clegg, B. (1980). An impact soil test as alternative to California bearing ratio. In Proceedings $3 r d$ Australia-New Zealand conference on geomechanics, pp. 225-230. Wellington, New Zealand: New Zealand Institution of Engineers.

Clifford, J. M. (1978). Evaluation of compaction plant and methods for the construction of earthworks in Southern Africa. Dissertation in partial fulfilment of the requirements for the degree of Master of Science in Engineering, University of Natal, Durban, South Africa.

Heyns, S. (1998). Response analysis of an impact compactor, Report LGI98/013, Project 020-DP. Pretoria, South Africa: Laboratory for Advanced Engineering Pty Ltd., University of Pretoria.
Jha, K. K., Suksawang, N., Lahiri, D. \& Agarwal, A. (2012). Energy-based analysis of nanoindentation curves for cementitious materials. ACI Mater. J. 109, No. 1, 81-90.

Labview (2018). http://www.ni.com/en-us/shop/labview.html (accessed 26/10/2018).

Mayne, P. W. \& Jones, J. S. (1983). Impact stresses during dynamic compaction. J. Geotech. Engng, ASCE 109, No. 10, $1342-1346$

McCann, K. (2015). The use of impact compaction for the near surface compaction on dredged sand land reclamation projects. In Proceedings of the 12th Australia-New Zealand conference on geomechanics (ed. G. Ramsay), pp. 1193-1200. Wellington, New Zealand: New Zealand Geotechnical Society.

McCann, K. \& Schofield, N. (2007). Innovative methods in the in-situ determination of design parameters on heterogeneous sites subject to ground treatment using deep impact compaction. In Proceedings of the 10th Australia-New Zealand conference on geomechanics (eds J. Ameratunga, B. Taylor and M. Patten), vol. 2, pp. 126-131. Brisbane, Australia: Australian Geomechanics Society.

Mooney, M. A. \& Rinehart, R. V. (2007). Field monitoring of roller vibration during compaction of subgrade soil. J. Geotech. Geoenviron. Engng, ASCE 133, No. 3, 257-265.

Scott, B. T., Jaksa, M. B. \& Syamsuddin, E. (2016). Verification of an impact rolling compaction trial using various in situ testing methods. In Proceedings of the 5th international conference on geotechnical and geophysical site characterisation (eds B. M. Lehane, H. E. Acosta-Martínez and R. Kelly), pp. 735-740. Sydney, Australia: Australian Geomechanics Society.

Thong, Y. K., Woolfson, M. S., Crowe, J. A., Hayes-Gill, B. R. \& Challis, R. E. (2002). Dependence of inertial measurements of distance on accelerometer noise. Meas. Sci. Technol. 13, No. 8, $1163-1172$.

Yu, X. (2004). Field evaluation of ground stiffness by static and dynamic tests. Electron. J. Geotech. Engng 9, No. D. See http:// www.ejge.com/2004/Ppr0442/Abs0442.htm (accessed 22/03/2019). 